\title{
Scientific genius is extinct
}

\section{Dean Keith Simonton fears that surprising originality in the natural sciences is a thing of the past, as vast teams finesse knowledge rather than create disciplines.}

$\mathrm{M}$ any scientists devote their careers to studying phenomena that they can assume will not go away anytime soon. Life forms will always undergo change across generations, so evolutionary biologists will always have a job. But the very phenomenon that I investigate might have actually ceased to exist.

I have devoted more than three decades to studying scientific genius, the highest level of scientific creativity ${ }^{1}$. The creative scientist contributes ideas that are original and useful. The scientific genius, however, offers ideas that are original, useful and surprising. Such momentous leaps - be they theories, discoveries or inventions - are not just extensions of already-established, domain-specific expertise: the scientific genius conceives of a novel expertise.

Albert Einstein's special theory of relativity met these three criteria and required introductory-level textbooks to be rewritten. Einstein overthrew the Newtonian concept of absolute space and time, and revealed a groundbreaking relationship between matter and energy, denoted in his famous equation, $E=m c^{2}$.

Geniuses have played a decisive part in science in two main ways. First, they have founded new scientific disciplines, such as Galileo's creation of telescopic astronomy. Second, geniuses have revolutionized established disciplines. Charles Darwin, for instance, proposed that species evolve by natural selection at a time when many biologists believed that life forms were fixed from the moment of Biblical creation.

Yet, in my view, neither discipline creation nor revolution is available to contemporary scientists. Our theories and instruments now probe the earliest seconds and farthest reaches of the Universe, and we can investigate the tiniest of life forms and the shortestlived of subatomic particles. It is difficult to imagine that scientists have overlooked some phenomenon worthy of its own discipline alongside astronomy, physics, chemistry and biology. For more than a century, any new discipline has been a hybrid of one of these, such as astrophysics, biochemistry or astrobiology. Future advances are likely to build on what is already known rather than alter the foundations of knowledge. One of the biggest recent scientific accomplishments is the discovery of the Higgs boson - the existence of which was predicted decades ago.

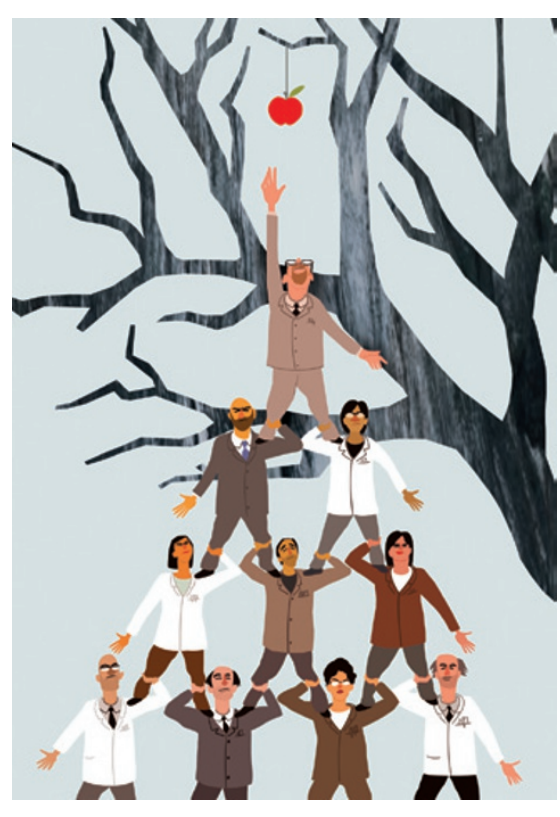

The days when a doctoral student could be the sole author of four revolutionary papers while working full time as an assistant examiner at a patent office - as Einstein did in 1905 - are probably long gone. Natural sciences have become so big, and the knowledge base so complex and specialized, that much of the cutting-edge work these days tends to emerge from large, well-funded collaborative teams involving many contributors.

\section{SCIENCE OLYMPIANS}

At this point, let me add three clarifications. First, I am not saying that scientific progress will cease. On the contrary, I believe that the scientific enterprise will continue to get "faster, higher, stronger". Textbook chapters will continue to be updated. At worst, some disciplines will asymptotically approach some ill-defined limit of precision and comprehensiveness, much as seems to be happening in many competitive sports. Just as athletes can win an Olympic gold medal by beating the world record only by a fraction of a second, scientists can continue to receive Nobel prizes for improving the explanatory breadth of theories or the preciseness of measurements. These laureates still count as 'Olympian scientists'.

Second, I am not arguing that science is becoming 'dumbed down', or that modern investigators are less intelligent than Nicolaus Copernicus, René Descartes, Isaac
Newton, Marie Curie or Louis Pasteur. Contemporary scientists generally have very high IQs ${ }^{2}$. If anything, scientists today might require more raw intelligence to become a first-rate researcher than it took to become a genius during the 'heroic age' of the scientific revolution in the sixteenth and seventeenth centuries, given how much information and experience researchers must now acquire to become proficient. It is hard to know whether Pierre-Simon Laplace or James Clerk Maxwell would have been bright enough to master the formidable mathematics of superstring theory, for instance.

Finally, I am not asserting that brilliant scientists can no longer attempt to introduce new paradigms, or even to devise original disciplines. It is just that such innovations seem less likely to catch on. According to Thomas Kuhn's classic analysis of scientific revolutions, a discipline within the physical and biological sciences should not even be receptive to a paradigm shift unless the discipline is in a state of crisis, produced by the accumulation of critical findings that continue to resist explanation ${ }^{3}$. For example, special relativity resolved the impasse set in motion by, among other things, the 1887 experiment by US physicists Albert Michelson and Edward Morley that failed to detect the universal 'ether' assumed to help propagate electromagnetic waves .

Most, if not all, disciplines in the natural sciences do not seem close to this crisis state. The core disciplines have accumulated not so much anomalies as mere loose ends that will be tidied up one way or another. A possible exception is theoretical physics, which is as yet unable to integrate gravity with the other three forces of nature.

Of course, I hope that my thesis is incorrect. I would hate to think that genius in science has become extinct and that my research speciality has become obsolete. It takes only one new scientific genius to prove me wrong.

Dean Keith Simonton is professor of psychology at the University of California at Davis, California 95616, USA.

e-mail:dksimonton@ucdavis.edu

1. Simonton, D. K. Scientific Genius: A Psychology of Science (Cambridge Univ. Press, 1988).

2. Simonton, D. K. Creativity in Science: Chance, Logic, Genius, and Zeitgeist (Cambridge Univ. Press, 2004).

3. Kuhn, T. S. The Structure of Scientific Revolutions (Univ. Chicago Press, 1996). 